\title{
Article
}

\section{Redefining Authentic Research Experiences in Introductory Biology Laboratories and Barriers to Their Implementation}

\author{
Rachelle M. Spell, ${ }^{*}$ Judith A. Guinan, ${ }^{\dagger}$ Kristen R. Miller, ${ }^{\ddagger}$ \\ and Christopher W. Beck ${ }^{*}$
}

\author{
*Emory University, Atlanta, GA 30322; ${ }^{\dagger}$ Radford University, Radford, VA 24142; ${ }^{*}$ University of Georgia, Athens, \\ GA 30602; §Flinders University, Adelaide, SA 5001, Australia
}

Submitted October 13, 2013; Revised December 11, 2013; Accepted December 14, 2013

Monitoring Editor: Nancy Pelaez

\begin{abstract}
Incorporating authentic research experiences in introductory biology laboratory classes would greatly expand the number of students exposed to the excitement of discovery and the rigor of the scientific process. However, the essential components of an authentic research experience and the barriers to their implementation in laboratory classes are poorly defined. To guide future reform efforts in this area, we conducted a national survey of biology faculty members to determine 1) their definitions of authentic research experiences in laboratory classes, 2) the extent of authentic research experiences currently experienced in their laboratory classes, and 3) the barriers that prevent incorporation of authentic research experiences into these classes. Strikingly, the definitions of authentic research experiences differ among faculty members and tend to emphasize either the scientific process or the discovery of previously unknown data. The low level of authentic research experiences in introductory biology labs suggests that more development and support is needed to increase undergraduate exposure to research experiences. Faculty members did not cite several barriers commonly assumed to impair pedagogical reform; however, their responses suggest that expanded support for development of research experiences in laboratory classes could address the most common barrier.
\end{abstract}

\section{INTRODUCTION}

Over the past $15 \mathrm{yr}$, numerous reports have called on science faculty to bridge research and teaching in order to attract more undergraduates to science, technology, engineering, and mathematics (STEM) fields (Boyer Commission on Educating Undergraduates in the Research University, 1998; Project Kaleidoscope, 2002; National Research Council [NRC], 2003, 2005). More recently, the American Association for the Advancement of Science (AAAS) Vision and Change report urged the integration of research experiences into biology education for all students (AAAS, 2011). The goal of

DOI: $10.1187 /$ cbe.13-08-0169

Address correspondence to: Rachelle M. Spell (rspell@emory.edu).

(C) 2014 R. M. Spell et al. CBE-Life Sciences Education (C) 2014 The American Society for Cell Biology. This article is distributed by The American Society for Cell Biology under license from the author(s). It is available to the public under an AttributionNoncommercial-Share Alike 3.0 Unported Creative Commons License (http:/ / creativecommons.org/licenses/by-nc-sa/3.0).

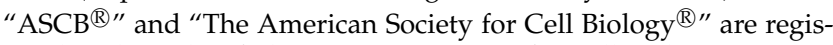
tered trademarks of The American Society for Cell Biology. these reforms is authentic science instruction that reflects better what scientists do and how scientists think.

These directives are based on many studies showing the positive impact of traditional undergraduate research experiences, alternatively called mentored, independent, or collaborative research, in which a student works in a laboratory or in the field on a project with some faculty oversight (reviewed by Seymour et al., 2004; Lopatto, 2006; Russell et al., 2007; Crowe and Brakke, 2008; Laursen et al., 2010). The number of students who can have such a traditional research experience is limited, however, because of factors such as lack of funding (President's Council of Advisors on Science and Technology, 2012). In contrast, all science students take laboratory classes. Unfortunately, the traditional laboratory experience in lab classes, with "cookbook" experiments in which students follow a predetermined methodology and then prepare an artificial scientific report, is not effective for teaching scientific content or the process of science (Myers and Burgess, 2003; Luckie et al., 2004; Rissing and Cogan, 2009). Such canned activities can foster an unrealistic view of science as prescriptive, unambiguous, and irrelevant and therefore do not reflect "authentic" science (Bencze and Hodson, 1999; Rahm et al., 2003; NRC, 2005). 
Because research-oriented laboratory courses can provide many of the same advantages as traditional mentoredresearch opportunities (Lopatto, 2009) and can reach more students, recent efforts have been made to introduce authentic research experiences in laboratory courses. Attempts to incorporate the process of science into the lab exercises have resulted in several different lab course models that vary in level of student independence and in the types of research questions addressed (examples are reviewed in Graham et al., 2013). These different course-based research projects focus on different aspects of authentic research. If support for research experiences is to be expanded to laboratory instruction, it is important to define the essential components of an authentic research experience in a laboratory course.

The essential components of mentored research include reading scientific literature, designing aspects of the research project, working toward significant findings, and oral and written presentation of the results (Seago, 1992; Lopatto, 2003). Several publications have attempted to define the level of research experiences in laboratory class, using terms like inquiry (e.g., guided inquiry, open-ended inquiry, teachercollaborative inquiry, and authentic inquiry), authentic, or research-based (D'Avanzo, 1996; Olson and Loucks-Horsley, 2000; Rahm et al., 2003; Buck et al., 2008; Weaver et al., 2008; Bencze and Hodson, 2009). However, the use of any one definition may not reflect the vision of biology faculty about incorporating authentic research experiences in the classroom. Education reform toward authentic science instruction includes definitions of authentic science as a process (involving critical thinking, hypothesis generation, experimental design, data analysis, and scientific communication) or as a product (novel results, new discoveries, and publishable data). This lack of a clear definition or adherence to a definition not universally held could impede acceptance, implementation, and funding for course-based research experiences.

Other barriers to pedagogical reform could limit the expansion of research experiences into laboratory courses. Insufficient training, time, and incentive are among the most commonly cited barriers for faculty change to reform teaching (for a review of the literature, see Brownell and Tanner, 2012). Additional potential barriers include struggles with professional identity (Brownell and Tanner, 2012); logistical issues, such as adequate funding and persons to implement teaching reform (Kloser et al., 2011); and faculty attitude that traditional teaching formats are sufficient, because the students who experience such formats do graduate and get jobs (Benvenuto, 2002).

Efforts to broaden exposure to science inquiry through authentic research experiences in laboratory courses could be hampered by assumptions and lack of information about the essential components of authentic research experiences in these courses and the barriers to their implementation. Henderson et al. (2011) note that, to bring about change in pedagogical approaches, those changes must align with the pedagogical values of faculty involved. To support faculty members' efforts to answer calls for research for all biology students, it is important to gauge their views of the critical components of experiences that mimic authentic research, determine the extent of current implementation of authentic research in courses, and identify the barriers that prevent the expansion of those experiences.
Previous surveys of laboratory courses have explored the types of experiences offered in introductory biology laboratory classes. A survey of members of the Ecological Society of America at 131 institutions found a very low level of openended investigations in 1996 (Brewer, 1998). The most recent report of the status of introductory biology laboratories was in 2005, with a survey of 65 institutions, asking faculty to report whether lab experiences incorporated inquiry-based or open-ended investigations (Sundberg and Armstrong, 1993; Sundberg et al., 2005). Sundberg and colleagues found a high level of inquiry-based experiences in all institution types, but open-ended investigations were less common, especially in research and comprehensive institutions. The information from these surveys, now outdated, provided no information about the degree to which these research approaches are used in a laboratory course nor the faculty members' views of the critical components of research in laboratory classes.

Research Experiences in Introductory Laboratories (REIL)Biology is a network of faculty interested in exploring questions related to authentic research in introductory biology laboratory courses. In particular, we want to expand professional development opportunities for faculty to create authentic research experiences in laboratory classes. To inform efforts to provide authentic research experiences for all students through laboratory courses, we surveyed instructors nationally to determine their views on the essential components of authentic research experiences in introductory biology laboratory courses, the level to which these experiences are incorporated in these courses, and the perceived barriers to implementing them.

\section{METHODS}

\section{Survey Development and Implementation}

We developed and carried out a national survey on authentic research experiences in introductory biology laboratory courses (see the Supplemental Material). The survey was developed at a meeting of 12 faculty members involved in the REIL-Biology Research Coordination Networks in Undergraduate Biology Education (RCN-UBE) incubator project (http:/ / rcn.ableweb.org), along with core participants in the Introductory Biology Project (http:/ / ibp.ou.edu). The survey asked faculty to define the essential components of an authentic research experience in a laboratory course. Based on their definitions, faculty members were asked to provide demographic information about the introductory biology laboratory courses they taught at their institutions, including the percentage of those courses devoted to authentic research, and to rank the importance of particular barriers to the implementation of authentic research. The survey was widely disseminated through email lists of the biology education community, including the education sections of disciplinary societies, the American Institute of Biological Science, the Association for Biology Laboratory Education, and the Council on Undergraduate Research (CUR).

\section{Survey Response Coding and Analysis}

Coding Authentic Research Definitions. Definitions of authentic research were coded in a two-step process. First, NVivo software (QSR International, Burlington, MA) was 
used to create a list of the most frequently provided words (and variations thereof) in the definitions of authentic research. These terms and their variations were used to create broad categories of descriptive expressions common to the majority of definitions. The categories included the words: "experiment," "data," "question," "research," "design," "hypothesis," "presentation," and "results." We then used the process of thematic analysis to refine the categories and capture specific themes (and their frequencies) that occurred within them. This process allowed categories to be considered within the context of entire responses rather than just in light of frequency of individual terms. For example, the word "experiment" was the most common term found across all definitions. However, deeper examination clarified that, in most cases, survey respondents were referring to students creating their own experimental designs to answer a question.

To begin the analysis, one of us (C.W.B.) reviewed all definitions and categories and provided a preliminary coding scheme of six themes within the definitions. These included novel questions (i.e., unknown results), student-generated questions, hypothesis formation, experimental design, data analysis, and presentation or publication. Two of us (R.M.S. and K.R.M.) then coded a random subset of definitions $(n=$ 40) using the themes. We used Krippendorff's alpha to compare the interrater reliability of applied codes. Themes that resulted in low interrater reliability were discussed until mutual agreement was reached on understanding what a theme represented and how it should be coded. Finally, three of us (C.W.B., R.M.S., and K.R.M.) coded the remaining definitions. For all themes, the interrater reliability was greater than 0.70 . Therefore, for definitions not coded the same by the three of us, we used the coding of the majority. During the coding, a seventh theme, data collection, emerged and was coded for all definitions. Eighty-eight percent of the definitions included at least one of the seven themes. Many of the definitions that did not fit the defined themes were caused by the respondents' failure to directly address the question.

Identification of Additional Barriers. An open-ended portion of the survey allowed respondents to provide additional barriers to implementation of authentic research experiences. Eighty-six responses were recorded; some responses included multiple additional barriers. Seventy-eight instances were examples or elaborations of barriers listed in the survey. However, 22 new, distinct barrier categories also emerged from the data, and frequencies of these barriers were recorded.

\section{Statistical Analyses}

Definitions of Authentic Research. We used a Spearman correlation test to determine the relationship between the themes that were suggested by respondents' definitions of authentic research. To determine whether the presence or absence of particular themes differed significantly among institution types, we performed Pearson $\chi^{2}$ analyses. A Kruskal-Wallis rank-sum test was used to determine whether the number of themes selected varied significantly based on institution types.

Factors Influencing the Percent Authentic Research Incorporated into Laboratory Exercises. Because the variable percent research was nonnormally distributed and attempts to transform it were ineffective, we analyzed the factors influencing the amount of authentic research incorporated into laboratories using nonparametric methods. We used a Spearman's correlation to examine the relationship between percent research and the number of course sections for each course reported in the surveys. To compare the percent research in courses (averaged across all courses reported by each respondent) taught by individuals who included a particular theme with those who did not include that theme, we used Wilcoxon rank-sum tests. We determined whether the percent research varied according to the number of themes suggested by respondents' definition of authentic research using a Kruskal-Wallis rank-sum test. To determine the relationship between institution or course type and percent research, we averaged responses across course type for each respondent and binned them into categories as follows: $0 \%$, 0-25\%, 26-50\%, 51-75\%, and 76-100\%. We then determined the relationship between the binned categories and institution and course type using Pearson $\chi^{2}$ analyses.

Analysis of Reported Barriers to Including Authentic Research Experiences. We used Kruskal-Wallis rank-sum tests to examine the influence of institution type (e.g., research university, 2-yr college, etc.) on the distribution of responses for each of the barriers. Differences in perceptions of barriers between faculty from minority and non-minority serving institutions were tested using Wilcoxon rank-sum tests. Similarly, we compared the perceptions of barriers of faculty from private and public institutions using Wilcoxon ranksum tests. Finally, we used Wilcoxon rank-sum tests to determine whether there were differences in perceived barriers depending on whether particular themes were included in faculty definitions of authentic research.

All analyses were performed using JMP, version 9.0.0 statistical software (SAS Institute, Cary, NC).

\section{RESULTS}

\section{Sample}

Our national survey elicited 279 responses across institution types (2-yr college: 17\%; liberal arts college: $41 \%$; comprehensive university: $13 \%$; research university: $20 \%$; not stated: $9 \%$ ), equally split between public and private institutions. Fourteen percent of responses were from minority-serving institutions. Respondents provided data on 534 courses, the majority of which were courses for majors (Figure 1). The vast majority of respondents were leaders in these courses $(76 \%$ instructors and $15 \%$ directors). The frequency of responses for courses serving majors, nonmajors, and mixed (majors and nonmajors) did not differ among institution types $\left(\chi^{2}=6.38\right.$, $d f=6, p=0.39$ ). However, courses for prehealth students were more common at 2-yr colleges in our sample (Figure 1).

\section{Definitions of Authentic Research}

A word-frequency search of open-ended responses to our question about the essential components of an authentic research experience in a laboratory course identified seven common themes (in order of decreasing frequency): 1) experimental design $(n=145), 2)$ data collection $(n=136), 3)$ data analysis $(n=131), 4)$ presentation or publication $(n=$ $103), 5)$ hypothesis formation $(n=89), 6)$ student-generated 


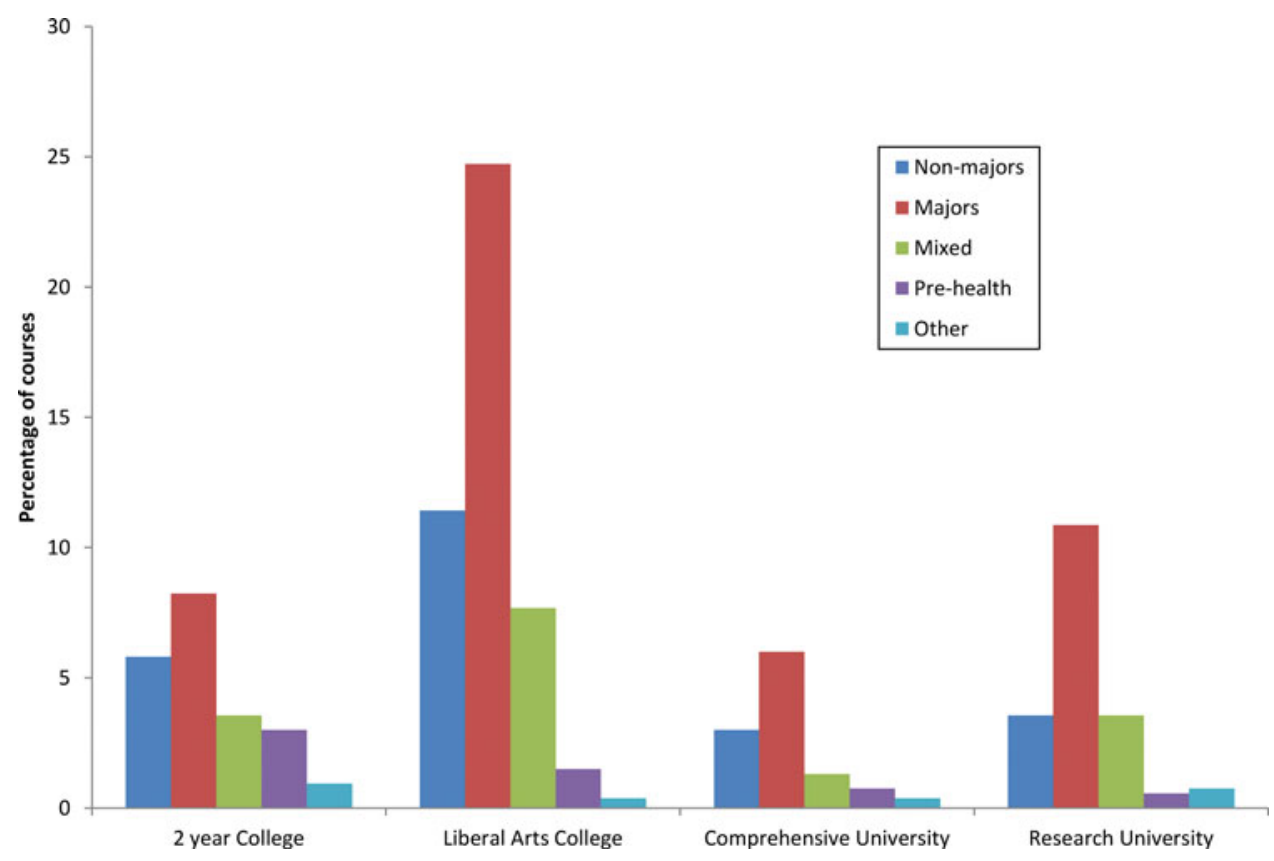

Figure 1. Percentage of course types by institution type.

questions ( $n=83)$, and 7$)$ novel questions $(n=62)$. Fewer than $15 \%$ of definitions failed to fit at least one of these themes, often because of confusion over the question being asked. Most responses included more than one theme (Figure 2). The number of themes (Kruskal-Wallis test, $\chi^{2}=7.72, d f=3, p=0.052$ ) and the presence or absence of particular themes (chi-square goodness-of-fit tests, $p>0.05$ ) were not significantly affected by institution type.

Two conceptions of authentic research in laboratory courses emerged. The more common conception emphasized the process of science, often incorporating multiple themes except the novel questions theme (Figures 2 and 3). The less common conception emphasized novel research questions to the exclusion of the other themes (Figure 3). In other words, when a respondent included only a single theme, it was most often the novel questions theme (Figure 2). In most cases, the themes were significantly positively correlated (Table 1), but the presence of the novel questions theme in a response was either significantly negatively correlated or uncorrelated with the inclusion of all other themes (Table 1), supporting the idea of two different conceptions of authentic research in laboratory courses (Figure 3).

\section{Level of Authentic Research}

Students in introductory biology laboratory courses spend on average a third of their time on authentic research activities; however, the amount of authentic research incorporated into individual courses is variable, ranging from 0 to $100 \%$ (Figure 4A). Twenty-three percent (23\%) of courses have no

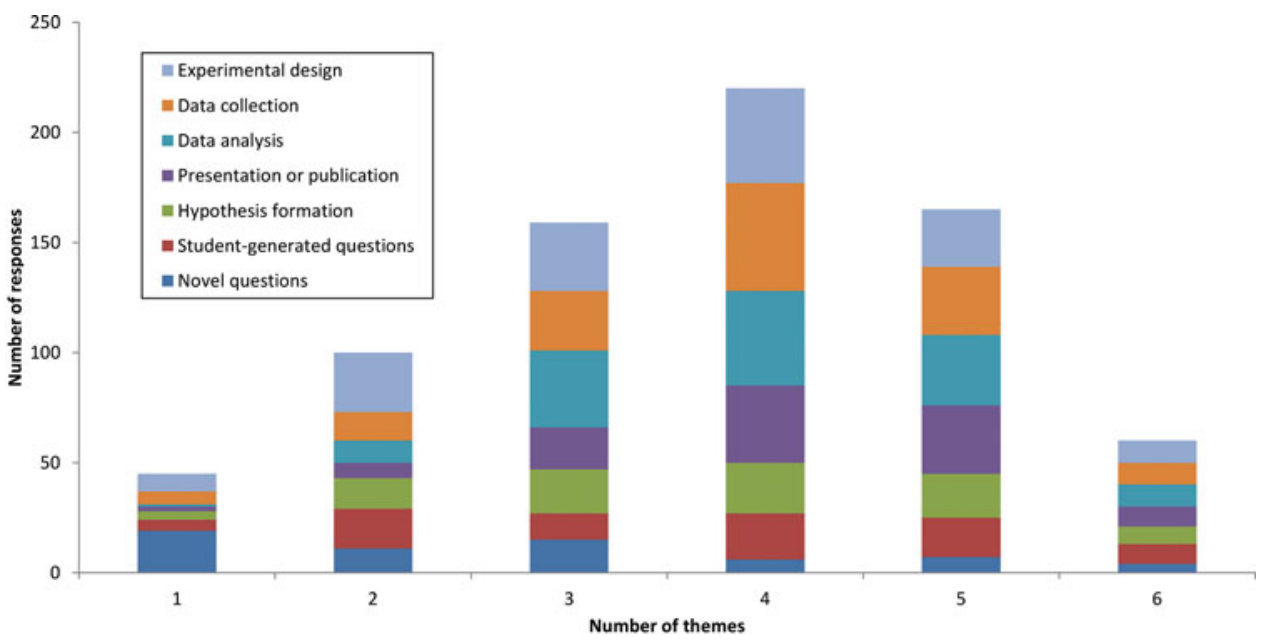

Figure 2. Frequency of different themes in definitions of authentic research by number of themes included in respondents' definitions of authentic research. 


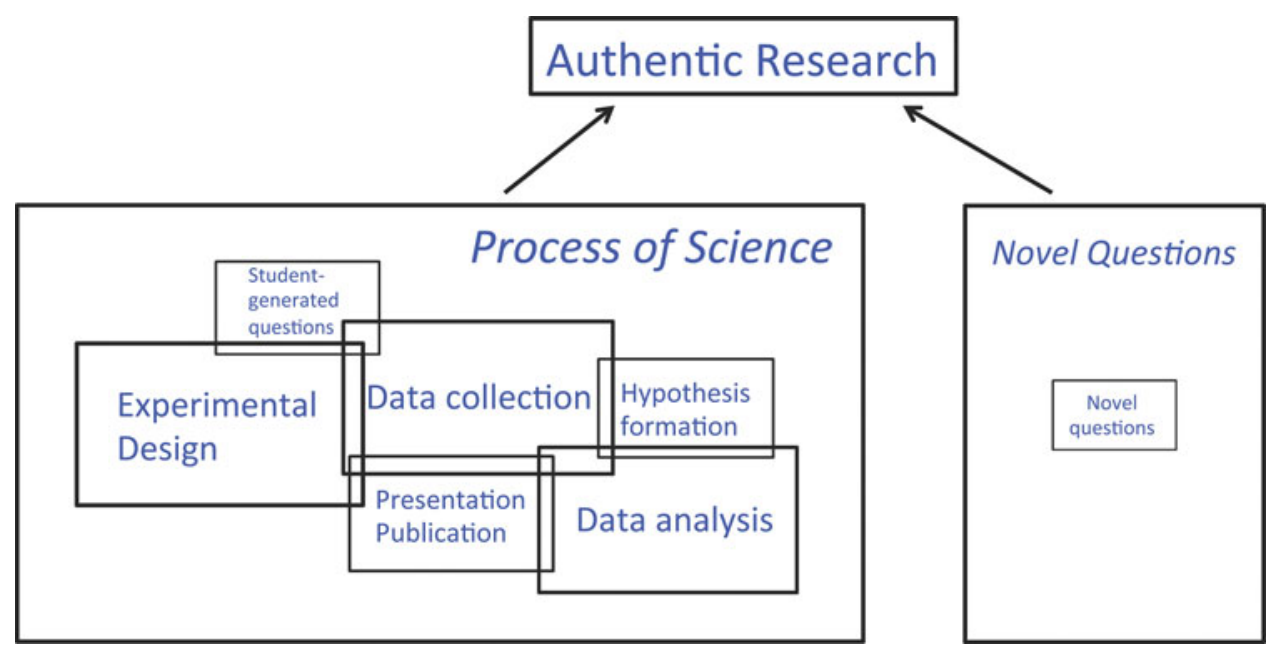

Figure 3. Two conceptions of authentic research based on relationships among themes. The size of each box is proportional to the frequency of a theme. Overlap of themes represents significant positive correlations between themes in definitions with more than one theme. Nine of 11 significant positive correlations are depicted. See Table 1 for the Spearman rank correlations between themes.

research, and $56 \%$ devote less than a quarter of course time to research. The amount of research in a course is not affected by the number of themes included in a respondent's definition of authentic research (Kruskal-Wallis test, $\chi^{2}=5.28$, $d f=6, p=0.44$ ) or which themes were included (Wilcoxon rank-sum test, $p>0.15$ for all themes). However, research is much less common in nonmajors courses $\left(\chi^{2}=26.93, d f=1\right.$, $p<0.001)$ and at 2-yr colleges $\left(\chi^{2}=9.87, d f=1, p=0.002\right.$; Figure $4 \mathrm{~B})$. The percentage of research in a course also decreases as the number of sections of a course increases (Spearman rank correlation, $r=-0.167, p=0.0002$ ).

\section{Barriers to Implementing Authentic Research}

A summary of the most and least important barriers based on the most frequent faculty response (mode) is given in Table 2 (see Supplemental Table S1 for overall summary statistics and Tables S2-S4 for summary statistics by institution type). Across all institution types, lack of time to develop new laboratory research experiences was reported as the biggest barrier to implementation of authentic research in laboratory courses for most faculty (mode of 4 out of 4 on a Likert scale where 1 = "not a barrier," 2 = "minor barrier," $3=$ "somewhat a barrier," and $4=$ "major barrier"; Tables 2 and S1).
Furthermore, additional barriers were considered to be major barriers by faculty at specific institution types (mode $=4$; Tables 2 and S2-S4). In some cases, a potential barrier was, in fact, not a barrier (mode $=1$; Table S1) when we examined the data across all faculty but was considered a major barrier (mode $=4$ ) for a subset of faculty (e.g., lack of administrator support and instructor resistance at minority-serving institutions; Table S3).

When we compared the importance of potential barriers between institution types statistically, we found the reports of several barriers differed significantly (Tables S2-S4). For example, faculty at 2-yr colleges indicated that lack of time for faculty to develop new research activities and lack of student preparation were significant barriers, whereas faculty at research universities identified large class sizes and large number of sections to be significant barriers (Table S2). Faculty at minority-serving institutions identified lack of administrator support, lack of facilities, and lack of time to develop new research experiences as significant barriers (Table S3). Cost, lack of equipment, number of sections, and lack of student preparation are perceived to be significantly greater barriers by faculty at public institutions in contrast to faculty at private institutions (Table S4). The barriers due to number of sections and lack of student preparation exhibit the most noticeable differences in modal response between faculty at public and

Table 1. Spearman rank correlations between different themes in the definitions of authentic research

\begin{tabular}{|c|c|c|c|c|c|c|c|}
\hline & $\begin{array}{l}\text { Novel } \\
\text { questions }\end{array}$ & $\begin{array}{c}\text { Student-generated } \\
\text { questions }\end{array}$ & $\begin{array}{l}\text { Hypothesis } \\
\text { formation }\end{array}$ & $\begin{array}{l}\text { Presentation } \\
\text { or publication }\end{array}$ & $\begin{array}{l}\text { Data } \\
\text { analysis }\end{array}$ & $\begin{array}{l}\text { Data } \\
\text { collection }\end{array}$ & $\begin{array}{c}\text { Experimental } \\
\text { design }\end{array}$ \\
\hline Novel questions & 1 & -0.18 & -0.20 & 0.04 & -0.11 & -0.21 & -0.16 \\
\hline Student-generated questions & -0.18 & 1 & -0.01 & 0.04 & 0.11 & 0.13 & 0.25 \\
\hline Hypothesis formation & -0.20 & -0.01 & 1 & 0.15 & 0.27 & 0.21 & 0.06 \\
\hline Presentation or publication & 0.04 & 0.04 & 0.15 & 1 & 0.37 & 0.43 & 0.20 \\
\hline Data analysis & -0.11 & 0.11 & 0.27 & 0.37 & 1 & 0.50 & 0.27 \\
\hline Data collection & -0.21 & 0.13 & 0.21 & 0.43 & 0.50 & 1 & 0.22 \\
\hline Experimental design & -0.16 & 0.25 & 0.06 & 0.20 & 0.27 & 0.22 & 1 \\
\hline
\end{tabular}

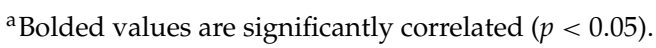



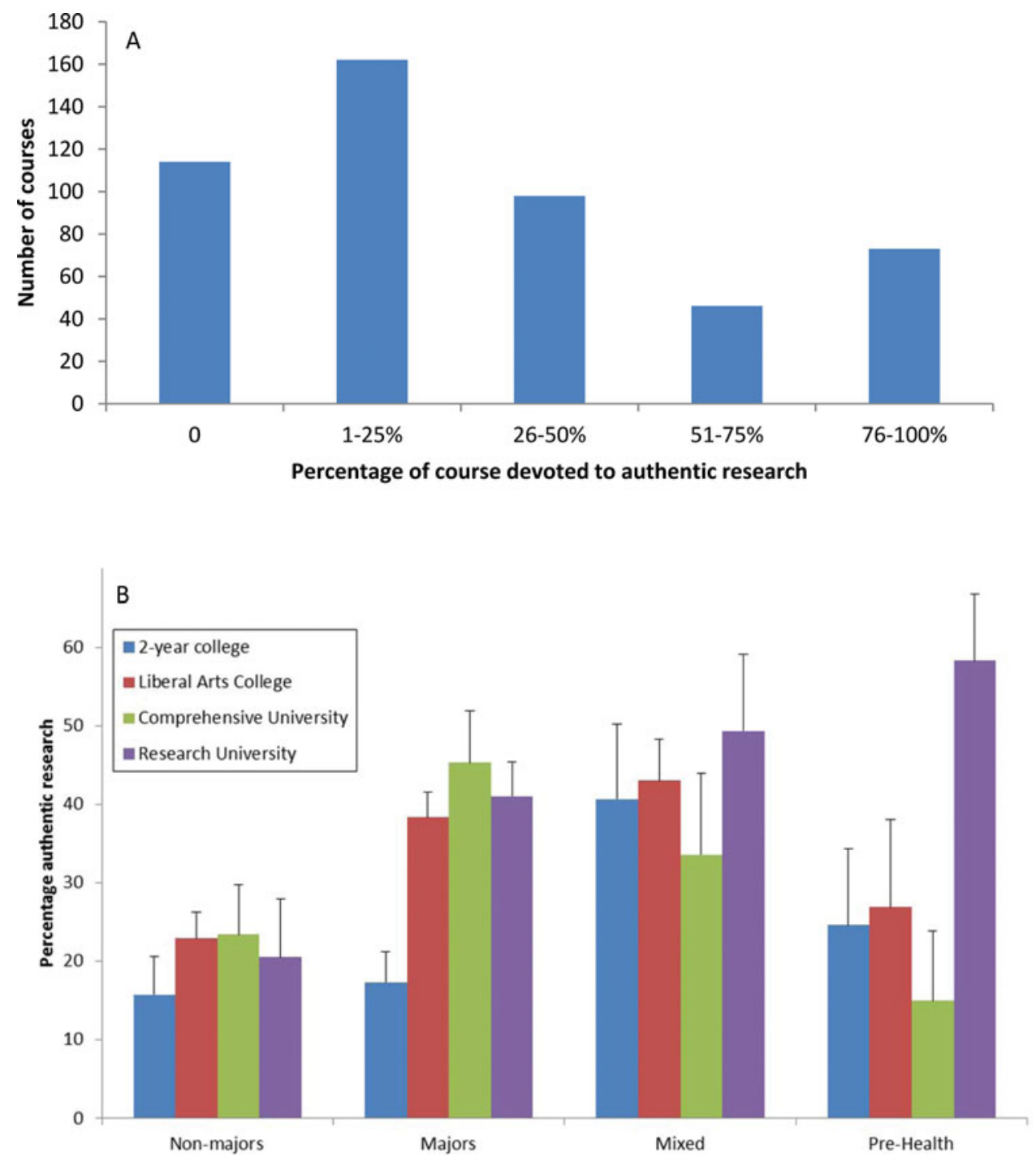

Figure 4. The percentage of a course devoted to authentic research experiences (A) for all courses in our total sample and (B) for courses divided by institution type and course type. Error bars represent standard errors.

private institutions (Table S4). Additional barriers listed in free responses fell into multiple, small categories $(n=22)$, including time for implementation, logistics, student attitudes, connection with lecture, creativity, and curricular resources (Table S5), which suggests a strong contextual influence on implementation of authentic research experiences. Overall, the primary barriers to implementing authentic research (Table S1) did not differ depending on how a respondent defined authentic research, except that those faculty members who included the theme of experimental design considered lack of student preparation to be more of a barrier $\left(\chi^{2}=4.35\right.$, $d f=1, p=0.037$ ).

Some of the potential barriers included in the survey were not considered to be barriers by faculty respondents. Instructor resistance, lack of administrator support, lack of facilities, effects on student evaluation of instructors, loss of content coverage and breadth, lack of ways to effectively assess student were all most often perceived to be not a barrier (mode $=$ 1; Tables 2 and S1). In particular, more than half of the respon- dents considered lack of administrator support and effects on student evaluation of instructors not to be a barrier (median; Table S1). However, it is important to note that the degree to which some of these potential barriers were considered to be (un)important varied among institution types (Table S2), between minority and nonminority institutions (Table S3), and between public and private institutions (Table S4).

\section{DISCUSSION}

This study examined the definitions of authentic research in the context of introductory biology laboratory courses, the level of research experiences in these courses, and the barriers to implementing authentic research according to faculty members who teach these courses. Surprisingly, our survey found different understandings of the essential components of authentic research and highlighted errors in conventional wisdom about barriers to implementing research experiences 
Table 2. Summary of barriers to implementation of authentic research experiences in introductory biology laboratory classes, based on Likert-scale modes

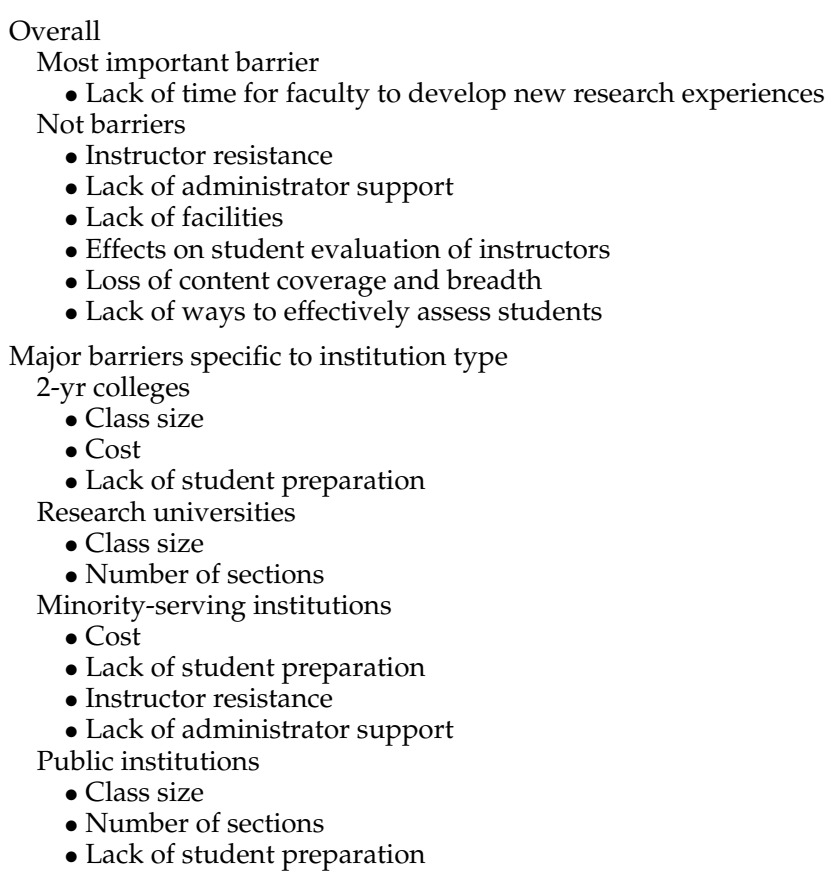

in laboratory courses. The survey sampled a large number of faculty members representing many courses in all institutions types, but, of course, the results could be biased by differences between those who responded versus those who did not. It is possible, for example, that faculty members who offer research opportunities in laboratory courses were more likely to respond, inflating the percent of laboratory instruction that involves research experiences reported in our study. Also, conceptions of authentic research and barriers to its implementation likely vary from individual to individual and institution to institution. Finally, characteristics of authentic research experiences may also be different in upper-level courses. In short, there is no one "best" definition of authentic research and no single barrier to overcome. Thus, this study emphasizes the need to discuss definitions and measure barriers before directing education reform. If we do not, we run the risk of wasting efforts and ignoring real barriers. In a time of federal reevaluation of best practices for supporting STEM education reform (Mervis, 2013), such analyses are even more critical.

The results of our survey suggest two conceptions of the essential components of authentic research in introductory biology laboratory courses (Figure 3 ). The predominant conception relates to the process of science. In contrast, the less frequent conception emphasizes exclusively novel research questions. Clearly, the essential components of research experiences in laboratory courses that emerged from our survey overlap with those defined by Lopatto (2003) for mentored research experiences. However, given the emphasis on science process over novel results in most responses, all faculty do not perceive authentic research in a laboratory course as simply migrating mentored research into a course context and scal- ing it up. The intention of this study is not to choose which conception is correct but rather to measure the prevalence of both views.

These two conceptions likely arise in part because of the difference in their primary goals. Whereas the main objective of mentored research is to produce science (i.e., publishable, novel results), the main objective of research in laboratory courses is to produce scientists (i.e., students who understand the process of science). This dichotomy has been described as a conflict between "products" versus "process" (Rahm et al., 2003) or "science-as-a-noun" versus "science-asa-verb" (Apedoe et al., 2006). Both goals still reflect authentic science instruction, in that they reflect what scientists do in their own research laboratories. Although these goals are distinct, they do not have to be exclusive; a well-mentored research lab should strive to develop future scientists while generating new data. Efforts to increase authentic research in laboratory courses need to recognize that definitions of authentic research are context dependent. Faculty who implement research courses under different goals should be sensitive to the limitations of either conception. Thus, faculty members who develop course-based research that emphasizes student-generated questions and experimental design but may not generate publishable data could provide extra discussion of the rigor of the scientific process and publication during their courses. Likewise, faculty members who oversee research activities that generate publishable data, often addressing a faculty-defined hypothesis using established protocols, could intentionally include exercises in student experimental design. Though some models of authentic research in courses that include both conceptions exist, they are rare, and it would be unrealistic to require both in all models of course-based research activities.

Different successful models of authentic research experiences in laboratory courses demonstrate the diversity of approaches. Previous efforts have developed specific model systems for research-based laboratory courses (e.g., Research Link 2000, www.cur.org/projects_and_services/research_ link_2000). In addition, model projects implementing research experiences in college laboratory courses are being used across multiple institutions (e.g., the Genome Consortium for Active Teaching [Campbell et al., 2006, 2007], Integrated Microbial Genomes Annotation Collaboration Toolkit [Ditty et al., 2010], Howard Hughes Medical Institute [HHMI] Phage Hunters [Hanauer et al., 2006], Genomics Education Partnership [Shaffer et al., 2010], Ecological Research as Education Network [Bowne et al., 2011]). Several examples of research laboratory courses explore topics that derive from the instructors' research programs (e.g., Bell, 2011; Gardner et al., 2011; Gasper et al., 2012). Many of these projects focus predominantly on the conception of authentic research related to novel results, in which the research question or the methods are defined by the instructor. The Course-Based Undergraduate Research Experience Network is working to bring together many of these models. On the other hand, models of laboratory activities incorporating student-generated questions and experimental design are commonly described in the literature as open-ended inquiry. In many cases, these exercises do not generate publishable data.

Some examples of authentic research in courses show ways in which the two different conceptions of authentic research 
can be combined, even at the introductory level. For example, Jacob (2012) has designed a semester-long course in which students design their own experiments to examine aspects of microbial diversity on a granite rock outcrop using molecular methods. Similarly, Fukami (2013) describes an introductory biology laboratory course in which students design experiments related to his research program on flowering plants, their pollinators, and the microbes in the nectar. In both cases, students are addressing novel questions while working through all aspects of the process of science (Figure 3). These examples more closely mirror the teacher-collaborative approach described by D'Avanzo (1996), in which students have varying degrees of independence, the research project is controlled by both students and faculty, and the outcome of the project is unknown.

Previous surveys of inquiry-based learning in biology laboratory courses showed high percentages of courses incorporating inquiry but that open-ended experiments in which students are defining the research question and the research methods were rare (Brewer, 1998; Sundberg et al., 2005). The one exception to the general trend was at liberal arts colleges, where $50 \%$ of institutions used open-ended experiments (Sundberg et al., 2005). Neither survey asked explicitly about authentic research experiences (Brewer, 1998; Sundberg et al., 2005). In fact, Sundberg et al. (2005) considered open-ended experiments to constitute authentic research. The results of our survey showed similar levels of authentic research, with greater than $50 \%$ of courses spending less than a quarter of the course on authentic research activities. The similarity between the current and past surveys overall suggests this survey is a representative sampling of research experiences in laboratory courses and the barriers that limit them. However, the current survey showed comparable levels of authentic research between liberal arts colleges, comprehensive universities, and research universities. Faculty at 2 -yr colleges report using authentic research experiences less frequently. Not surprisingly, the lowest levels of authentic research were found in nonmajors courses. Therefore, to bring about the vision of research experiences for all students we will need to redouble our efforts at 2-yr colleges and in courses targeted for nonmajors.

The low percentage of courses that incorporate more authentic research experience suggests that substantial barriers exist to implementing these experiences in introductory laboratory courses. Interestingly, many commonly cited barriers to the implementation of pedagogical reform in STEM were not perceived to be substantial barriers by our survey respondents (see Supplemental Table S1; Benvenuto, 2002; Brownell and Tanner, 2012; Kloser et al., 2011). For example, instructor resistance is low, and administrator support is not limiting in most cases (although, as noted, lack of administrator support is perceived to be a major barrier for faculty at minorityserving institutions). Furthermore, laboratory course instructors do not seem concerned about a loss of content coverage. Our results suggest that time for faculty to develop new research experiences is the most pressing need. Furthermore, the variation in responses to our question about barriers indicates the need to clearly identify barriers for individuals at particular institutions and not assume that all individuals and institutions are the same. The individualization of pedagogical reform is critical (Henderson et al., 2011).
Recently, Brownell and Tanner (2012) suggested that the professional identity of faculty as researchers rather than teachers serves as a barrier to change in pedagogy. Professional identity was not included as one of the potential barriers in our survey (see the Supplemental Material). However, it was not listed as an additional barrier by any of our survey respondents (Table S5). Yet integrating a faculty member's research program into a laboratory course would be an ideal way in which to overcome this potential barrier (e.g., Chen et al., 2005; Kloser et al. 2011; Fukami, 2013; Miller et al., 2013).

On the basis of the results of our survey, we propose several ways in which to address the challenge of the Vision and Change report to provide research experiences in biology for all students. First, to expand efforts by researchers to introduce research into the curriculum, research grant supplements should be offered to scientists (similar to Research Experiences for Undergraduates supplements) to partner with science faculty with education specialties (SFES; Bush et al., 2013), postdoctoral fellows, or graduate students to develop research-based curricula for introductory laboratories for use at their institution or as modules for broader dissemination. Second, to expand the opportunity for education specialists to develop such exercises, funded fellowships should be made available for SFES to work with researchers. Last, to address the most common barrier to implementing authentic research experiences, faculty need time for professional and curriculum development, for example workshops funded by RCN-UBE, Transforming Undergraduate Education in Science, Technology, Engineering and Mathematics, and HHMI. In all cases, faculty members participating in these programs need to begin by defining the essential components of an authentic research experience for their contexts and identifying the barriers that need to be addressed.

\section{ACKNOWLEDGMENTS}

We thank members of the REIL-Biology network for their contributions in crafting the survey and providing feedback on a draft of the manuscript. We also thank Arri Eisen for his comments. All data reported in the paper are presented in the Supplemental Material. All authors contributed to writing the survey and the final manuscript. J.A.G. conducted the statistical analyses. R.M.S., K.R.M., and C.W.B. coded the responses to the question on definitions of authentic research. This research was supported by grant DBI-1061798 from the National Science Foundation (NSF) to Emory University. Any opinions, findings, and conclusions or recommendations expressed in this material are those of the authors and do not necessary reflect the views of the NSF.

\section{REFERENCES}

American Association for the Advancement of Science (2011). Vision and Change: A Call to Action, Washington, DC.

Apedoe X, Walker SE, Reeves TC (2006). Integrating inquiry-based learning into undergraduate geology laboratories. J Geosci Educ 54, 414-421.

Bell E (2011). Using research to teach an "introduction to biological thinking." Biochem Mol Biol Educ 39, 10-16.

Bencze L, Hodson D (1999). Changing practice by changing practice: toward more authentic science and science curriculum development. J Res Sci Teach 36, 521-539. 
Benvenuto M (2002). Educational reform: why the academy doesn't change. Thought and Action Fall, 63-74.

Bowne DR et al. (2011). Transforming ecological science at primarily undergraduate institutions through collaborative networks. BioScience 61, 386-392.

Boyer Commission on Educating Undergraduates in the Research University (1998). Reinventing Undergraduate Education: A Blueprint for America's Research Universities, Stony Brook: State University of New York.

Brewer CA (1998). Preliminary results of the ESA survey on ecology in the undergraduate curriculum. Bull Ecol Soc Am 79, 106107.

Brownell SE, Tanner KD (2012). Barriers to faculty pedagogical change: lack of training, time, incentives, and tensions with professional identity. CBE Life Sci Educ 11, 339-346.

Buck LB, Bretz SL, Towns MH (2008). Characterizing the level of inquiry in the undergraduate laboratory. J Coll Sci Teach 38, 5258.

Bush SD, Pelaez NJ, II JAR, Stevens MT, Tanner KD, Williams KS (2013). Widespread distribution and unexpected variation among science faculty with education specialties (SFES) across the United States. Proc Natl Acad Sci USA 110, 7170-7175.

Campbell AM, Eckdahl TT, Fowlks E, Heyer LJ, Hoopes LLM, Ledbetter ML, Rosenwald AG (2006). Genome Consortium for Active Teaching (GCAT). Science 311, 1103-1104.

Campbell AM, Ledbetter ML, Hoopes LL, Eckdahl TT, Heyer LJ, Rosenwald A, Fowlks E, Tonidandel S, Bucholtz B, Gottfried G (2007). Genome Consortium for Active Teaching: meeting the goals of BIO2010. CBE Life Sci Educ 6, 109-118.

Chen J et al. (2005). Discovery-based science education: functional genomic dissection in Drosophila by undergraduate researchers. PLoS Biol 3, e59.

Crowe M, Brakke D (2008). Assessing the impact of undergraduate research experiences on students: an overview of current literature. CUR Quart 28, 43-50.

D'Avanzo C (1996). Three ways to teach ecology labs by inquiry: guided, open-ended, and teacher-collaborative. Bull Ecol Soc Am 77, 92-93.

Ditty JL et al. (2010). Incorporating genomics and bioinformatics across the life sciences curriculum. PLoS Biol 8, e1000448.

Fukami T (2013). Integrating inquiry-based teaching with faculty research. Science 339, 1536-1537.

Gardner SM, Adedokun OA, Weaver GC, Bartlett EL (2011). Human brains engaged in rat brains: student-driven neuroanatomy research in an introductory biology lab course. J Undergrad Neurosci Educ 10, A24-A36.

Gasper BJ, Minchella DJ, Weaver GC, Csonka LN, Gardner SM (2012). Adapting to osmotic stress and the process of science. Science 335, 1590-1591.

Graham M, Frederick J, Byars-Winston A, Hunter A-B, Handelsman $\mathrm{J}$ (2013). Increasing persistence of college students in STEM. Science 341, 1455-1456.

Hanauer DI, Jacobs-Sera D, Pedulla ML, Cresawn SG, Hendrix RW Hatfull GF (2006). Teaching scientific inquiry. Science 314, 1880-1881.

Henderson C, Beach A, Finkelstein N (2011). Facilitating change in undergraduate STEM instructional practices: an analytic review of the literature. J Res Sci Teach 48, 952-984.

Jacob NP (2012). Investigating Arabia Mountain: a molecular approach. Science 335, 1588-1589.

Kloser M, Brownell S, Chiariello N, Fukami T (2011). Integrating teaching and research in undergraduate biology laboratory education. PLoS Biol 9, e1001174.
Laursen S, Hunter A-B, Seymour E, Thiry H, Melton G (2010). Undergraduate Research in the Sciences: Engaging Students in Real Science, San Francisco: Wiley.

Lopatto D (2003). The essential features of undergraduate research. CUR Quart 24, 139-142.

Lopatto D (2006). Undergraduate research as a catalyst for liberal learning. Peer Rev 8, 22-25.

Lopatto D (2009). Science in Solution: The Impact of Undergraduate Research on Student Learning, Tucson, AZ: Research Corporation.

Luckie DB, Maleszewski JJ, Loznak SD, Krha M (2004). Infusion of collaborative inquiry throughout a biology curriculum increases student learning: a four-year study of "Teams and Streams." Adv Physiol Educ 28, 199-209.

Mervis J (2013). Wild cards remain after proposed reshuffle of STEM education. Science 340, 258-259.

Miller CW, Hamel J, Holmes KD, Helmey-Hartman WL, Lopatto D (2013). Extending your research team: learning benefits when a laboratory partners with a classroom. BioScience 63, 754-762.

Myers MJ, Burgess AB (2003). Inquiry-based laboratory course improves students' ability to design experiments and interpret data. Adv Physiol Educ 27, 26-33.

National Research Council (NRC) (2003). BIO2010. Transforming Undergraduate Education for Future Research Biologists, Washington, DC: National Academies Press.

NRC (2005). America's Lab Report: Investigations in High School Science, Washington, DC: National Academies Press.

Olson S, Loucks-Horsley S (eds.) (2000). Inquiry and the National Science Education Standards: A Guide for Teaching and Learning, Washington, DC: National Academies Press.

President's Council of Advisors on Science and Technology (2012). Report to the President: Engage to Excel: Producing One Million Additional College Graduates with Degrees in Science, Technology, Engineering, and Mathematics, Washington, DC: Executive Office of the President.

Project Kaleidoscope (2002). Recommendations for Action in Support of Undergraduate Science, Technology, Engineering, and Mathematics: Report on Reports, Washington, DC.

Rahm J, Miller HC, Hartley L, Moore JC (2003). The value of an emergent notion of authenticity: examples from two student/teacherscientist partnership programs. J Res Sci Teach 40, 737-756.

Rissing SW, Cogan JG (2009). Can an inquiry approach improve college student learning in a teaching laboratory? CBE Life Sci Educ $8,55-61$.

Russell SH, Hancock MP, McCullough J (2007). The pipeline. Benefits of undergraduate research experiences. Science 316, 548-549.

Seago JL (1992). The role of research in undergraduate instruction. Am Biol Teach 54, 401-405.

Seymour E, Hunter AB, Laursen SL, Deantoni T (2004). Establishing the benefits of research experiences for undergraduates in the sciences: first findings from a three-year study. Sci Educ 88, 493-534.

Shaffer CD et al. (2010). The Genomics Education Partnership: successful integration of research into laboratory classes at a diverse group of undergraduate institutions. CBE Life Sci Educ 9, 55-69.

Sundberg MD, Armstrong JE (1993). The status of laboratory instruction for introductory biology in US universities. Am Biol Teach 55, 144-146.

Sundberg MD, Armstrong JE, Wischusen EW (2005). Reappraisal of the status of introductory biology laboratory education in US colleges and universities. Am Biol Teach 67, 525-529.

Weaver GC, Russell CB, Wink DJ (2008). Inquiry-based and research-based laboratory pedagogies in undergraduate science. Nat Chem Biol 4, 577-580. 